\title{
Enhancing Effect of Aged Garlic Extract on Induction of Morphological Differentiation with Neurite Outgrowth in NGF-Treated PC12 Cells
}

\author{
Kohfuku Kohda $^{{ }^{*}}$, Kei Itoh ${ }^{1}$, Hitomi Goda ${ }^{1}$, Keijiro Samejima ${ }^{1}$, Tomoko Fukuuchi ${ }^{1}$, Naoaki Morihara ${ }^{2}$, \\ Kazuhiko Imamura', Yukihiro Kodera ${ }^{2}$, Takami Oka ${ }^{2 *}$ \\ ${ }^{1}$ Graduate School of Pharmaceutical Sciences, Musashino University, Tokyo, Japan; ${ }^{2}$ Wakunaga Pharmaceutical Co., Ltd., Hiroshi- \\ ma, Japan. \\ Email: "kohda@musashino-u.ac.jp, "oka_tm@wakunaga.co jp
}

Received October $4^{\text {th }}, 2011$; revised November $20^{\text {th }}, 2011$; accepted December $30^{\text {th }}, 2011$

\begin{abstract}
Background: We have been searching effective compounds that can stimulate the growth and differentiation of nerve cells. We found previously that fulleren derivatives enhanced induction of morphological differentiation with neurite outgrowth in nerve growth factor (NGF)-treated PC12 cells. In the course of our further search for other effective compounds, we found the aged garlic extract (AGE) has the activity similar to fulleren. Methods: PC12 cells were used to examine the effectiveness of test compound. Results: AGE enhanced the stimulating effect of NGF to induce morphological differentiation with neurite outgrowth in PC12 cells. In order to examine the active constituents of AGE, it was fractionated into several components. The activity was mainly localized in the F1 fraction that contains low molecular weight polar compounds. S-Allylmercaptocysteine (SAMC) is one of the sulfur components of AGE present in F1 fraction and found to exhibit the enhancing effect similar to AGE. Conclusion: AGE had the ability to induce morphological differentiation with neurite outgrowth in NGF-treated PC12 cell and SAMC was one of its active constituents.
\end{abstract}

Keywords: Aged Garlic Extract; PC12 Cells; NGF; Differentiation; Neurite Outgrowth

\section{Introduction}

Nerve cells are lost with aging without regeneration. We have been searching for the effective compounds that can stimulate the growth, survival and function of nerve cells and thus may help improve senescence of the brain. We previously reported that some water-soluble fullerene derivatives that have strong antioxidant activity enhance induction of morphological differentiation with neurite outgrowth in nerve growth factor (NGF)-treated PC12 cells [1]. At present the mechanisms of action of fullerene is obscure, but we speculated that fullerenes scavenged neurotoxic active oxygen species that were produced by NADPH oxidase during differentiation into sympathetic neuron-like cells induced by NGF [2].

Using the PC12 cell culture system, we have surveyed various other substances, especially those having antioxidant activity. Among the compounds tested, we found that aged garlic extract (AGE) enhanced the effect of NGF on induction of morphological differentiation with neurite outgrowth. AGE also has been shown to improve

*Corresponding author. learning ability in senescence-accelerated mouse [3] and have trophic effect on the morphology of primary cultured hippocampal neurons from fetal rat brain [4]. AGE is an odorless product produced from prolonged extraction of fresh garlic with aqueous alcohol. Compared with the raw garlic, AGE contains more stable and antioxidant phytochemicals that can prevent oxidant damage [5]. In order to identify its active constituents, AGE was fractionated into several fractions and each fraction was examined for its activities. The F1 fraction, that contains low molecular weight polar compounds, showed the enhancing activity. Furthermore some major sulfur compounds such as S-allylcysteine (SAC) and S-allylmercaptcysteine (SAMC) present in F1 fraction [6,7] were examined and SAMC was found to possess the activity similar to AGE.

\section{Materials and Methods}

\subsection{Materials}

NGF (2.5S, mouse) was purchased from Upstate (Lake Placid, NY, USA). Dulbecco's minimal essential me- 
dium (D-MEM), trypsin-EDTA and horse serum were purchased from GIBCO Invitrogen (Carlsbad, CA, USA). Fetal bovine serum was purchased from Nichirei Biosciences Inc. (Tokyo, Japan). SAC and SAMC were synthesized as previously reported [8-10].

\subsection{Preparation of AGE}

AGE was prepared as follows; garlic cloves (Allium sativum L.) grown under controlled organic conditions without the use of chemical fertilizers, herbicides or pesticides were sliced and soaked in an aqueous ethanol solution and extracted/aged up to 20 months at room temperature. AGE used in this study contained SAC as a major sulfur-containing compound in the range of 1.6 $2.4 \mathrm{mg} / \mathrm{g}$ dry weight [11]. In addition, other constituents such as N- $\alpha$-(1-deoxy-D-fructos-1-yl)-L-arginine (Fru-Arg) and tetrahydro- $\beta$-carboline derivatives were identified $[12,13]$. The concentration of SAC was used to standardize the extract according to the US Pharmacopeia/Natural Formula garlic fluid extract monograph [14].

\subsection{Fractionation of AGE}

After ethanol was removed from the AGE extract under in vacuo, water was added to the original volume. The resulting AGE solution was fractionated by a hydrophobic resin MCI gel CHP20P column (Mitsubishi Chemical, Tokyo, Japan) with stepwise gradient elution (water, $10 \%(\mathrm{v} / \mathrm{v}) \mathrm{MeOH}, 50 \%(\mathrm{v} / \mathrm{v}) \mathrm{MeOH}$ to $\mathrm{MeOH})$ to give 4 fractions; water (MCI-NA), $10 \% \mathrm{MeOH}$ (MCI-A10), $50 \% \mathrm{MeOH}$ (MCI-A50), MeOH (MCI-A100), respectively. The fraction MCI-NA was dialyzed against dis- tilled water by BioDesignDialysis Tubing ${ }^{\mathrm{TM}}$ (cutoff: 3500) (BioDesign Inc. NY, USA) at $4^{\circ} \mathrm{C}$ for 3 days to obtain the outside (F1) and the inside (F2) solutions of the dialysis tube, respectively. F2 was subjected to ion exchange chromatography on a DEAE Toyopeal $650 \mathrm{M}$ column (Tosoh Co., Japan) with $0.05 \mathrm{M}$ Tris-HCl buffer (pH 8.0) and $0.05 \mathrm{M}$ Tris-HCl buffer (pH 8.0) containing $2 \mathrm{M} \mathrm{NaCl}$ to give $\mathrm{F} 3$ and F4, respectively. F3 and F4 were dialyzed against distilled water by BioDesignDialysis Tubing ${ }^{\mathrm{TM}}$ (cutoff: 3500 ) at $4^{\circ} \mathrm{C}$ for 3 days to remove the salt, and then the resulting each fraction was lyophilized. F1 contained low molecular weight polar compounds including fructose, arginine and SAC. F3 and F4 contained polysaccharides and protein [13,14]. MCI fractions contained hydrophobic compounds. Fractionation scheme of AGE was shown in Figure 1.

\subsection{Cell Culture Conditions and Assay Methods for Induction of Morphological Differentiation with Neurite Outgrowth in PC12 Cells}

Rat pheochromocytoma PC12 cells were purchased from the American Type Culture Collection (ATCC, Manassas, VA, USA). PC12 cells were plated and grown on collagen-coated tissue culture dishes in D-MEM containing $10 \%$ horse serum and $10 \%$ fetal bovine serum at $37^{\circ} \mathrm{C}$ under a humidified $5 \% \mathrm{CO}_{2}$ incubator. Cells were seeded on a collagen-coated 24-well dish or a 6-well dish $(1 \times$ $10^{4}$ cells/well or $4 \times 10^{4}$ cells/well, respectively) and incubated for 1 day before use. To induce the differentiation to form cells with neurites, the medium was changed to D-MEM without serum and the cells were cultured

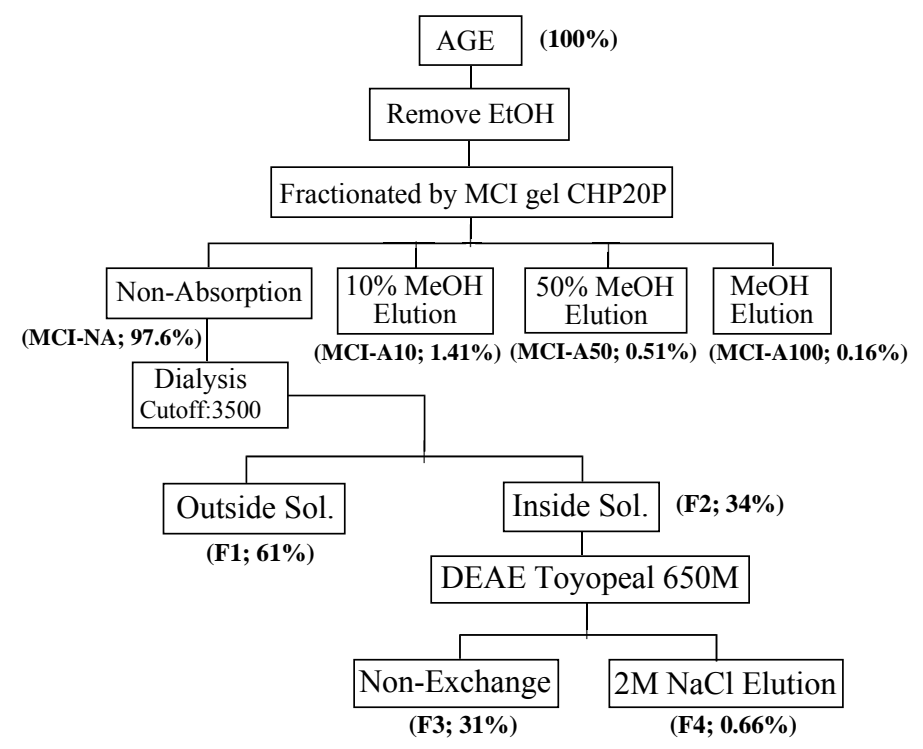

Figure 1. Fractionation scheme of AGE. The figure in parenthesis shows the yield (\%) of each fraction relative to the starting material. 
with $50 \mathrm{ng} / \mathrm{ml}$ of NGF in the presence or absence of AGE. After incubating for $72 \mathrm{~h}, \mathrm{PC} 12$ cells were examined under microscope. The number of cells with neurites having length longer than the diameter of one cell body was counted and the percentage of cells with neurites relative to the total number of cells was calculated. In addition, the length of the longest neurite of cell was measured. One hundred cells were examined in five to six different views in a dish in triplicate culture.

\subsection{Statistical Analysis}

The data were expressed as the mean \pm S.D. Statistically significant differences were determined using Student's $t$-test or one-way ANOVA followed by Bonferroni's multiple comparison test. ${ }^{* *} p<0.01$ and ${ }^{*} p<0.05$ were statistically significant.

\section{Results}

\subsection{Induction of Morphological Differentiation by AGE in NGF-Treated PC12 Cells}

Treatment of PC12 cells with NGF induced the formation of cells with neurites (Figures 2(a) and 2(b)). The effect of AGE was examined by varying its concentration from 0.1 to $2.5 \mathrm{mg} / \mathrm{ml}$ in PC12 cell culture [1]. AGE was not toxic even at the highest concentration tested, 2.5 $\mathrm{mg} / \mathrm{ml}$. As shown in Figure 3, the percentage of cells having neurites increased with the increasing the AGE concentration from 1.0 to $2.5 \mathrm{mg} / \mathrm{ml}$. Figure 2(c) showed the image of PC12 cells treated with NGF $(50 \mathrm{ng} / \mathrm{ml})+$ AGE $(2.5 \mathrm{mg} / \mathrm{ml})$; the increased number of differentiated cells with neurites and the elongation of neurite outgrowth can be seen.

\subsection{Induction of Morphological Differentiation with Neurite Outgrowth in NGF-Treated PC12 Cells}

The effect of AGE on induction of morphological differentiation into cells with neurites was shown in Figure 4(a). Treatment of PC12 cells with NGF $(50 \mathrm{ng} / \mathrm{ml}) \mathrm{re}-$ sulted in formation of cells with neurites that comprised $34 \%$ of cells. When AGE was present together with NGF, the proportion of cells with neurites increased to $49 \%$ and $53 \%$ in the presence of AGE at concentration of 1.25 $\mathrm{mg} / \mathrm{ml}$ and $2.5 \mathrm{mg} / \mathrm{ml}$, respectively. Even the highest concentration of AGE $(2.5 \mathrm{mg} / \mathrm{ml})$ showed no enhancing effect in the absence of NGF.

The effect of AGE on induction of neurite outgrowth in PC12 cells was shown in Figure 4(b). In the presence of NGF, the neurite outgrowth was stimulated by AGE. However, this effect required the higher concentration of AGE $(2.5 \mathrm{mg} / \mathrm{ml})$ when compared to that for induction of
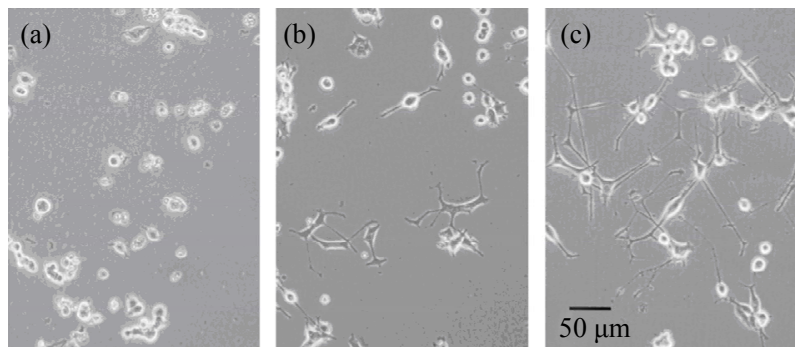

Figure 2. Phase contrast photomicrographs of PC12 cells. (a) control, (b) NGF $50 \mathrm{ng} / \mathrm{ml}$ and (c) NGF $50 \mathrm{ng} / \mathrm{ml}+$ AGE 2.5 $\mathrm{mg} / \mathbf{m l}$.

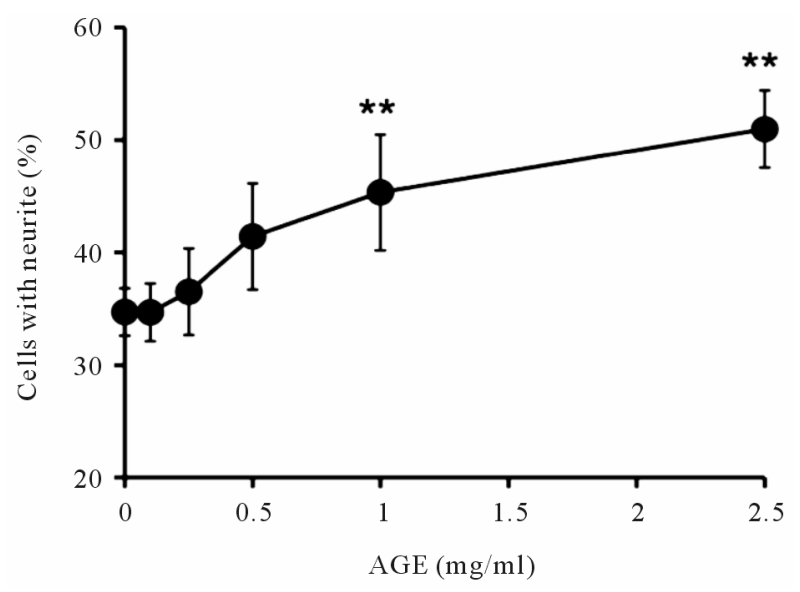

Figure 3. Effect of AGE concentration on induction of morphological differentiation in NGF-treated PC12 cells. The percentage of cells having neurites relative to total cell population is shown. The concentration of NGF used was 50 $\mathrm{ng} / \mathrm{ml}$. The same concentration of NGF was used throughout unless specified otherwise. ${ }^{* *} p<0.01$ vs. control cells without AGE treatment, $n=4$ - 6 .

the morphological differentiation (see Figure 4(a)). In the absence of NGF, no enhancing effect of AGE was observed. In the experiments to be described below, the induction of morphological differentiation was examined as a marker of the activity.

\subsection{Active Constituents of AGE}

In order to find the active components in AGE that enhanced the induction of morphological differentiation, AGE was fractionated into several components as shown in Figure 1. Then the effect of each fraction (F1, F3, F4, MCI-A10 (M10), MCI-A50 (M50) and MCI-A100 (M100)) on induction of the differentiation was examined. Each fraction was tested using concentration corresponding to that in $2.5 \mathrm{mg} / \mathrm{ml}$ of AGE. The results indicated that $\mathrm{F} 1$ possessed the enhancing activity but it was less compared with the whole AGE (Figure 5(a)), whereas F3 and F4 showed little activity. The re-constitution experiments were carried out by combining F1, F3 and F4 
(F-mix) according to their original ratio in AGE. The results indicated that only a weak activity similar to that with F1 was present in the F-mix. On the other hand, fractions M10, M50 and M100 and the mixture of these fractions (M-mix) had no effect, suggesting that hydrophobic components were not the active constituents (Figure 5(b)).

\subsection{Effects of SAC and SAMC}

It is known that AGE contains sulfur compounds such as SAC and SAMC and these are present in F1 fraction $[6,7]$. The effects of SAC and SAMC on induction of morphological differentiation in NGF-treated PC12 cells were examined. As shown in Figure 6(b), SAMC was active and its effect increased with its concentration up to $5.0 \mu \mathrm{g} / \mathrm{ml}$ and then reached plateu. No toxicity of SAMC was observed even at the highest concentration of 25 $\mu \mathrm{g} / \mathrm{ml}$. On the other hand, no enhancing effect of SAC

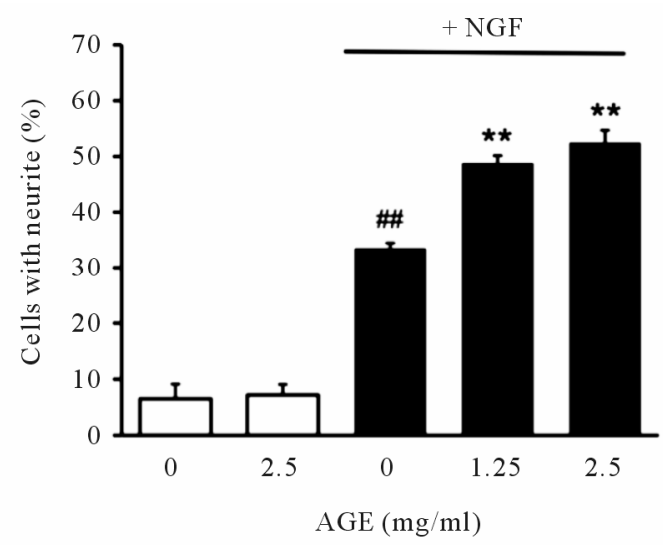

(a) was observed even at the concentration of $250 \mu \mathrm{g} / \mathrm{ml}$ (Figure 6(a)).

The effect of SAMC on the induction of morphological differentiation induced by NGF in PC12 cells was examined in the presence of various concentration of $\mathrm{NGF}$, i.e. $2.5,5.0,10,25$ and $50 \mathrm{ng} / \mathrm{ml}$. SAMC was added 0, 2.5 and $5.0 \mu \mathrm{g} / \mathrm{ml}$. As shown in Table 1, in the absence of SAMC the extent of the induction of morphological differentiation increased gradually with the concentration of NGF. The addition of SAMC further augmented the increase.

\section{Discussion}

We previously reported that water-soluble fullerene derivatives that have strong antioxidant activity had the ability to induce the morphological differentiation with the neurite outgrowth in NGF-treated PC12 cells [1]. In the course of our further study, we found that AGE exerts

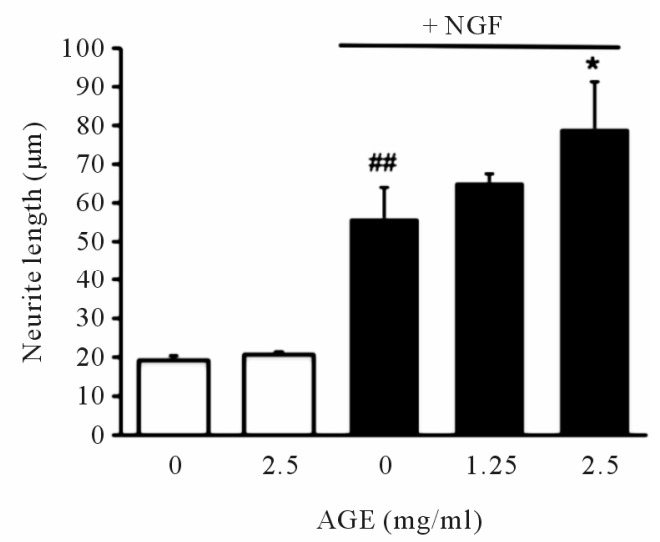

(b)

Figure 4. Effects of AGE on induction of both the morphological differentiation (a) and the neurite outgrowth (b) in NGF-treated PC12 cells. AGE was added at the indicated concentration. ${ }^{*} p<0.05$ and $* * p<0.01$ vs. NGF-treated control cells, ${ }^{\# \#}<0.01$ vs. control cells without NGF-treatment, $n=3$.

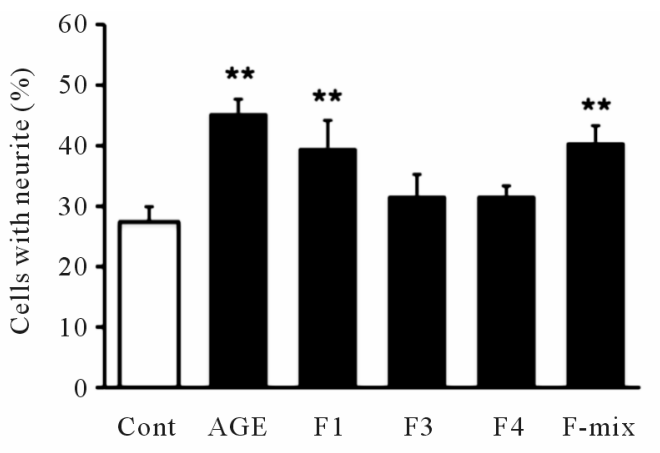

(a)

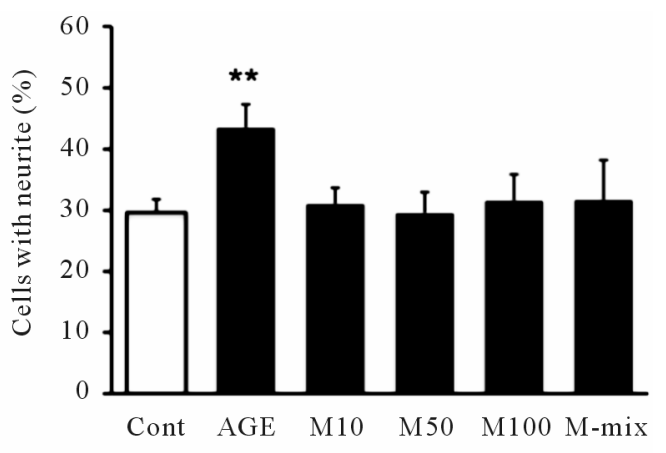

(b)

Figure 5. Effect of various AGE fractions and their combination on induction of morphological differentiation in NGF-treated PC12 cells. (a) and (b) show the effect of polar and non-polar fractions, respectively. Each fraction was obtained as described in Figure 1. The concentration of each fraction corresponded to that of $2.5 \mathrm{mg} / \mathrm{ml} \mathrm{of} \mathrm{AGE.**p<0.01} \mathrm{vs.}$ NGF-treated control cells, $n=3-4$. 


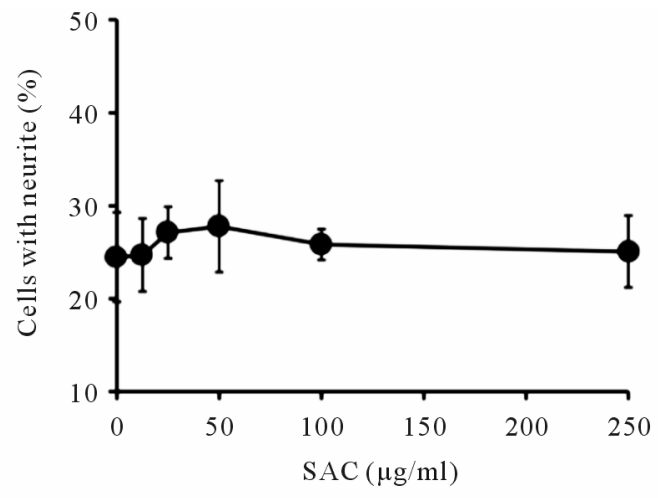

(a)

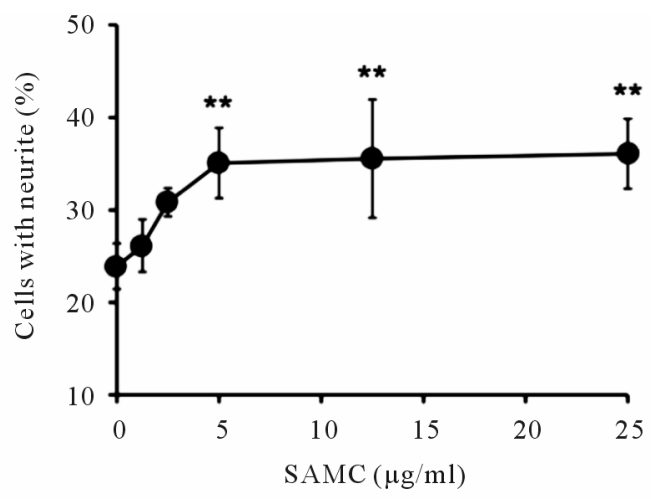

(b)

Figure 6. Effects of SAC (a) and SAMC (b) on induction of morphological differentiation in NGF-treated PC12 cells. $* * p<$ 0.01 vs. control cells without SAMC-treatment, $n=3$ - 4 .

similar effects on these cells. In addition, we found that SAMC was one of the active constituents in AGE.

Our data showed that for the induction of morphological differentiation, $1.25 \mathrm{mg} / \mathrm{ml}$ of AGE was optimal whereas $2.5 \mathrm{mg} / \mathrm{ml}$ of AGE was necessary for the maximal stimulation of neurite outgrowth (Figure 4). These results suggested that the mechanism of action of AGE to induce the morphological change is different from that involved in enhancement of the neurite outgrowth. Further, the enhancing effect of AGE was only observed in the presence of NGF, suggesting that AGE augmented the effect of NGF. It is reported that superoxide anion radicals were produced by NADPH oxidase when PC12 cells underwent differentiation into sympathetic neuron-like cells under the influence of NGF [2]. Since AGE can scavenge cytotoxic superoxide anion radicals [15], it could help the response of nerve cells to NGF, at least in part, by removing these radicals. With regard to the AGE stimulation of nerve cells, similar results were reported by Moriguchi et al. in the study of primary cultured hippocampal neurons from rat brain [7].

AGE was fractionated into several components and the activity of each fraction was examined. F1 showed some activity, but it was weaker than AGE whole (Figure 5(a)). On the other hand, F3 and F4 showed little activity and the F-mix (mixture of F1, F3 and F4) exhibited the activity very similar to that of F1. These results suggested that re-constitution was not achievable for some reason. It is possible that some loss or degradation of labile compounds occurred during the fractionation processes.

SAC and SAMC were major sulfur compounds present in AGE [6,7]. The activity to enhance PC12 cell differentiation was observed only with SAMC. Its maximum enhancing activity was found at the concentration of 5.0 $\mu \mathrm{g} / \mathrm{ml}$ (Figure 6(b)). As shown in Figure 3, AGE was most active at $2.5 \mathrm{mg} / \mathrm{ml}$. If we assume that the amount of SAMC in $2.5 \mathrm{mg}$ of AGE was approximately $1.25 \mu \mathrm{g}$, the most effective concentration of SAMC $(5.0 \mu \mathrm{g} / \mathrm{ml})$ exceeds that in AGE. It is possible that the enhancing effect of AGE may result from the combination of SAMC with some other AGE components.

With respect to the sulfur compounds having antioxidant properties in AGE, alliin, SAC and SAMC are all reported to have the ability to scavenge hydroxyl radical $[16,17]$. Both alliin and allicin can scavenge superoxide anion radical but not SAC and diallyl disulfide [17]. At present no data were available as to the ability of SAMC to scavenge superoxide anion radical, and the reason why only SAMC is effective remains not clear. SAMC has a disulfide bond that is easily metabolized to thiols in cells and these thiols may act as antioxidants. Similar findings were reported in the study of prevention of liver damage by SAMC but not SAC [18].

It is noteworthy that Ray et al. recently reported that both AGE and SAC showed the protective effect against the cytotoxicity induced by $\mathrm{H}_{2} \mathrm{O}_{2}$ in differentiated $\mathrm{PC} 12$ cells [19]. The results are consistent with the fact that both AGE and SAC can scavenge cytotoxic $\mathrm{OH}$ radical produced by $\mathrm{H}_{2} \mathrm{O}_{2}$.

We found that unlike NGF, AGE itself has no activity to induce neuronal differentiation. Experiments to assess the effect of SAMC on the potency of NGF revealed that SAMC increased the action of NGF (Table 1). It is not clear whether SAMC does so by scavenging superoxide produced by NGF.

In order to study the structure-activity relationship, we examined the effect of other related derivatives such as cysteine, cystine, diallyl sulfide, diallyl disulfide and dipropyl disulfide (data not shown). Cysteine showed no activity even at the concentration of $8.0 \mathrm{mM}$. Cystine was not tested due to its low solubility. Experiments using other derivatives were repeated several times, but the data were not conclusive due to large varietion of results. 
Table 1. The effect of SAMC in combination with NGF on induction of morphological differentiation in PC12 cells. ${ }^{\text {a) }}$

\begin{tabular}{cccccc}
\hline NGF $(\mathrm{ng} / \mathrm{ml})$ & 2.5 & 5.0 & 10 & 25 & 50 \\
\hline Control & $15.9 \pm 1.84$ & $18.8 \pm 1.58$ & $20.9 \pm 4.07$ & $24.6 \pm 2.98$ & $23.4 \pm 4.87$ \\
+ SAMC $2.5 \mu \mathrm{g} / \mathrm{ml}$ & $21.4 \pm 0.63(1.35)$ & $25.5 \pm 2.71(1.36)^{*}$ & $26.7 \pm 1.95(1.28)$ & $30.4 \pm 2.80(1.24)$ & $28.3 \pm 3.46(1.21)$ \\
+ SAMC $5.0 \mu \mathrm{g} / \mathrm{ml}$ & $25.4 \pm 4.30(1.60)^{* *}$ & $26.3 \pm 2.31(1.40)^{* *}$ & $29.7 \pm 1.21(1.42)^{* *}$ & $34.9 \pm 4.54(1.42)^{*}$ & $36.0 \pm 3.27(1.54)^{*}$ \\
\hline
\end{tabular}

${ }^{a)}$ Percentage of cell with neurite relative to the total number of cells was shown (mean \pm S.D.) The figure in parenthesis shows the enhanced ratio relative to the each control cell without SAMC-addition. ${ }^{*} p<0.05$ and ${ }^{* *} p<0.01$ vs. each control cell without SAMC-addition, $\mathrm{n}=3-4$.

One of the reasons for this may be the instability of such sulfur containing compounds due to autooxidation.

Garlic (Allium sativum L.) has been used for the prevention and treatment of a variety of diseases including heart disease and cancer [20]. AGE contains relatively stable antioxidant phytochemicals that may help prevent oxidative damages than garlic [5]. We hope AGE may be useful for improving senescence of the brain in near future after further studies and may provide good health benefits for human.

\section{Acknowledgements}

This study was supported in part by Musashino Jyosigaguin special Research Fund from 2008 to 2009.

\section{REFERENCES}

[1] H. Tsumoto, S. Kawahara, Y. Fujisawa, T. Suzuki, H. Nakagawa, K. Kohda and N. Miyata, "Syntheses of Water-Soluble [60] Fullerene Derivatives and Their Enhancing Effect on Neurite Outgrowth in NGF-Treated PC12 Cells," Bioorganic \& Medicinal Chemistry Letters, Vol. 20, No. 6, 2010, pp. 1948-1952. doi:10.1016/j.bmcl.2010.01.142

[2] M. Ibi, M. Katsuyama, C. Y. Fan, K. Iwata, T. Nishinaka, T. Yokoyama and C. Yabe-Nishimura, "NOX1/NADPH Oxidase Negatively Regulates Nerve Growth FactorInduced Neurite Outgrowth," Free Radical Biology \& Medicine, Vol. 40, No. 10, 2006, pp. 1785-1795. doi:10.1016/j.freeradbiomed.2006.01.009

[3] T. Moriguchi, K. Takashina, P. J. Chu, H. Saito and N. Nishiyama, "Prolongation of Life Span and Improved Learning in the Senescence Accelerated Mouse Produced by Aged Garlic Extract," Biological \& Pharmaceutical Bulletin, Vol. 17, No. 12, 1994, pp. 1589-1594. doi:10.1248/bpb.17.1589

[4] T. Moriguchi, N. Nishiyama, H. Saito and H. Katsuki, "Trophic Effects of Aged Garlic Extract (AGE) and Its Fractions on Primary Cultured Hippocampal Neurons from Fetal Rat Brain," Phytotherapy Research, Vol. 10, No. 6, 1996, pp. 468-472.

doi:10.1002/(SICI)1099-1573(199609)10:6<468::AID-PT R877>3.0.CO;2-I

[5] C. Borek, "Antioxidant Health Effects of Aged Garlic Extract," The Journal of Nutrition, Vol. 131, No. 3S, 2001, pp. 1010S-1015S.
[6] Y. Kodera, H. Matsuura, H. Sumiyoshi and S. Sumi, "Chemical and Biological Properties of Sulfur-Containing Compounds Derived from Garlic, Chapter 30," In: F. Shahidi, C. T. Ho, S. Watanabe and T. Osawa, Eds., Food Factors in Health Promotion and Disease Prevention, ACS Symposium Series Vol. 851, American Chemical Society, Washington DC, 2003, pp. 346-357.

[7] H. Amagase, B. L. Petesch, H. Matuura, S. Kasuga and Y. Itakura, "Intake of Garlic and Its Bioactive Components," The Journal of Nutrition, Vol. 131, No. 3S, 2001, pp. 955S-962S.

[8] Y. Kodera, A. Suzuki, O. Imada, S. Kasuga, I. Sumioka, A. Kanezawa, N. Taru, M. Fujikawa, S. Nagae, K. Yokoyama, K. Maeshige and K. Ono, "Physical, Chemical and Biological Properties of S-Allylcysteine, an Amino Acid Derived from Garlic," Journal of Agricultural and Food Chemistry, Vol. 50, No. 3, 2002. pp. 622-632.

[9] H. Hikino, M. Tokin, Y. Kiso, T. Namiki, S. Nishimura and K. Takeyama, "Antihepatotoxic Action of Allium sativum Bulbs,” Planta Medica, Vol. 52, No. 3, 1986, pp. 163-168. doi:10.1055/s-2007-969111

[10] I. Sumioka, T. Matsura, S. Kasuga, Y. Itakura and K. Yamada, "Mechanisms of Protection by S-allylmercaptocysteine against Acetoaminophen-Induced Liver Injury in Mice," Japanese Journal of Pharmacology, Vol. 78, No. 2, 1998, pp. 199-207. doi:10.1254/jip.78.199

[11] T. Moriguchi, H. Saito and N. Nishiyama, "Aged Garlic Extract Prolongs Longevity and Improves Spatial Memory Deficit in Senescence-Accerated Mouse," Biological \& Pharmaceutical Bulletin, Vol. 19, No. 2, 1996, pp. 305-307. doi:10.1248/bpb.19.305

[12] K. Ryu, N. Ide, H. Matsuura and Y. Itakura, "N Alpha(1-deoxy-D-fructos-1-yl)-L-arginine, an Antioxidant Compound Identified in Aged Garlic Extract," The Journal of Nutrition, Vol. 131, No. 3S, 2001, pp. 972S-976S.

[13] M. Ichikawa, K. Ryu, J. Yoshida, N. Ide, S. Yoshida, T. Sasaoka and S. Sumi, "Antioxidant Effects of Tetrahydro-beta-carboline Derivatives Identified in Aged Garlic Extract," Biofactors, Vol. 16, No. 3-4, 2002, 57-72. doi:10.1002/biof.5520160302

[14] United States Pharmacopeial Convention I, United States Pharmacopeia 28 Garlic Fluidextract USP 28-NF 23. United States Pharmacopeial Convention, Rockville, MD, 2005, pp. 2089-2090.

[15] N. Morihara, M. Hayama and H. Fujii, "Aged Garlic Extract Scavenges Superoxide Radicals," Plant Foods for Human Nutrition, Vol. 66, No. 1, 2011, pp. 17-21. 
doi:10.1007/s11130-011-0216-6

[16] J. Imai, N. Ide, S. Nagase, T. Moriguchi, H. Matsuura and Y. Itakura, "Antioxidant and Radical Scavenging Effects of Aged Garlic Extract and Its Constituents," Planta Medica, Vol. 60, No. 5, 1994, pp. 417-420. doi:10.1055/s-2006-959522

[17] L. Y. Chung, "The Antioxidant Properties of Garlic Compounds: Allyl Cysteine Alliin, Allicin and Allyl Disulfide," Journal of Medicinal Food, Vol. 9, No. 2, 2006, pp. 205-213. doi:10.1089/jmf.2006.9.205

[18] S. Nakagawa, S. Kasuga and H. Matsuura, "Prevention of Liver Damage by Aged Garlic Extract and Its Compo- nents in Mice," Phytotherapy Research, Vol. 3, No. 2, 1989, pp. 50-53. doi:10.1002/ptr.2650030203

[19] B. Ray, N. B. Chauhan and D. K. Lahiri, "Oxidative Insults to Neurons and Synapse Are Prevented by Aged Garlic Extract and S-allyl-L-cysteine Treatment in the Neuronal Culture and APP-Tg Mouse Model," Journal of Neurochemistry, Vol. 117, No. 3, 2011, pp. 388-402. doi:10.1111/j.1471-4159.2010.07145.x

[20] J. G. Dausch and D. W. Nixon, "Garlic: A Review of Its Relationship to Malignant Disease," Preventive Medicine, Vol. 19, No. 3, 1990, pp. 346-361. doi:10.1016/0091-7435(90)90034-H 